\title{
MECHANICAL BEHAVIOR AT LOW STRAINS LDPE FOAMS WITH CELL SIZES \\ IN THE MICROCELLULAR RANGE: ADVANTAGES OF USING THESE MATERIALS IN STRUCTURAL ELEMENTS
}

M.A. Rodriguez-Perez ${ }^{1, *}$, J.Lobos ${ }^{1}$, C. A. Perez-Muñoz ${ }^{1}$, J.A. de Saja ${ }^{1}$, L. Gonzalez ${ }^{2}$, M.A. del Carpio ${ }^{3}$.

1. Celllular Materials Group (CellMat), Condensed Matter Physics Department, University of Valladolid, 47011 Valladolid, Spain. Tel. +34 983 184035, Fax. +34983 423192, email:marrod@fmc.uva.es

2. Universidad Politécnica de Madrid, Departamento de Enseñanzas Básicas de la Ingeniería Naval, ETSI Navales, Madrid, Spain

3. ITPucel, Majadahonda, Madrid, Spain

\begin{abstract}
This paper presents the production method and the compressive mechanical response at low strains for a collection of polyethylene foams with high densities and cell sizes in the microcellular range. The materials were produced using a modified compression moulding technique that allows and independent control of density and cell size.

The materials had a relative density between 0.27 and 0.92 , an homogeneous and multistructured cellular structure with dense skin and foamed core and cell sizes in the range 30 to 100 microns. The Young's modulus was reduced when density did. For relative densities higher than 0.7 , the reduced Young's modulus of the foams was higher than that of the solid. In addition, it has been proved that variations in the cell size at constant density did not influence the Young's modulus. The advantages of using these materials for the production of plastic pipes have been analysed. A reduction of the weight of pipes loaded in compression of up to $42 \%$ can be reached by using these foams in spite of the solid material from which the foam was produced.
\end{abstract}


Key-words: Polyethylene foams, microcellular foams, mechanical properties.

\section{INTRODUCTION}

Microcellular plastics are foamed polymers characterised by cell sizes averaging 100 microns or less, typically between 5 and 50 microns [1]. These materials exhibit high Charpy impact strength, high toughness, high fatigue live, high thermal stability and low thermal conductivity [2] than solid polymers. Because of these unique properties, a large number of innovative applications can be imagined. These include food packaging with reduce materials costs, pipes or panels with improved strength to weight ratio, airplane and automotive parts with improved strength and acoustic dampening, sporting equipment with reduced weight and high energy absorption, etc. Due to these potential applications, over the last two decades substantial research and development has been conducted on the topic of microcellular processing and characterisation of microcellular products [3-10]

Microcellular plastics were initially produced at Massachusetts Institute of Technology (MIT) using a batch process [11] with three main steps, dissolution of a gas (mainly $\mathrm{CO}_{2}$ or $\mathrm{N}_{2}$ ) in the solid plastic, release of the pressure to create a supersaturated solid with gas, and heating of the material to promote expansion. This process has been mainly used to produce microcellular foams of amorphous materials with cells sizes around 10 microns [12].

The previous concept has been extended to the production of microcellular foams by injection moulding and extrusion [1,2, 13-15], and although considerable progress has been reached in these areas, there is still a need for further research. For instance, in 
injection moulding there is a poor surface quality of the produced products in conventional processing $[1,15]$, three is a limitation in the maximum size of the produced parts [1], and a limited weight reduction of the parts, not higher than $30-35 \%$ [1]. In extrusion, most of the studies have been performed at a laboratory scale or at a semi-industrial scale and as far as we know microcellular foams of semycristalline polymers are not produced industrially by extrusion. Only polystyrene has been successfully commercialised [12].

Other aspect in which the topic microcellular foams needs more detailed studies is connected with the mechanical characterisation of these products. Although several investigations have analysed the mechanical properties $[1,4,7-10]$ there is still a need to know the effect of cell size on the elastic response, the effect of the presence of a thick skin on the strength, the properties of these materials in comparison with foams produced from conventional technologies, etc.

Finally, another open aspect of interest is the identification of industrial areas in which these materials can play a key role [12]. One area of potential interest is the possibility of using the materials in plastic pipes of higher stiffness and lower weights with the idea of replacing the solid material. As it is expected that microcellular foams could have better mechanical properties than conventional foams this approach seems to be an interesting way of improving the properties of conventional pipes.

This paper focus on the following aspects: first a novel route to produce foams of semicrystalline polymers with cell sizes in the microcellular range is presented, second the elastic properties of these foams is characterised and third the potential of these materials for the production of plastics pipes is evaluated by performing finite element 
modelling. The aims of the paper are to gain knowledge on both the production, the structure-property relationships for foams of high density and with cell sizes in the microcellular range and the potential applicability of these materials.

\section{MATERIALS}

A low density polyethylene was used as matrix polymer $\left(\mathrm{MFI}=4 \mathrm{~g} / 10 \mathrm{~min}\right.$ at $190^{\circ} \mathrm{C}$, density $920 \mathrm{~kg} / \mathrm{m}^{3}$ ). Azodicarbonamide with a particle size of $4.9 \mu \mathrm{m}$ was used as blowing agent. Typical amounts of stearic acid and zinc oxide were used as processing aid and catalyser of the decomposition reaction of the blowing agent respectively [1618]. No crosslinking agents were used; therefore non crosslinked cellular materials were fabricated.

Foams were produced by a modified compression moulding technique [19]. In this process, first a precursor solid material that incorporates all the chemical compounds needed was produced by melt blending and compression moulding. Then the precursor material was famed as follows.

The precursor material that contains the blowing agent was inserted in a mould with an internal diameter equal to that of the precursor material (Figure 1). During the heating of the precursor material, which yields the blowing agent decomposition, a pressure high enough to avoid the foam expansion was applied by using a piston connected to a hydraulic press. When the entire blowing agent was generated, pressure was released and the piston moved to its final position. After this the mould is cooled and the stabilised foam is extracted from the mould. 
In this process, the foams grow under pressure, and the expansion ratio and as consequence the density is controlled by the displacement of the piston that applies the pressure. This has a significant advantage over the conventional compression moulding method [16-18] in which density is controlled by formulation and process parameters. In the modified compression moulding method density can be easily controlled and it is almost independent on the formulation. Due to this reason density and cell size can be controlled in an independent way.

Densities of the produced foams ranged between $250 \mathrm{~kg} / \mathrm{m}^{3}$ and $750 \mathrm{~kg} / \mathrm{m}^{3}$, i.e. relative densities in the range $0.27-0.92$. Cylindrical samples of $22.8 \mathrm{~mm}$ in diameter and 17.5 $\mathrm{mm}$ in height were used in the investigation.

\section{EXPERIMENTAL}

\section{Density measurements}

Density measurements were performed by Archimedes principle using the density determination kit for a AT261 Mettler balance.

\section{Scanning Electron Microscopy (SEM)}

Quantitative analysis was used to characterize the cellular structure. For this purpose, sections containing the sheets normal were microtomed at low temperature to provide a smooth surface that was vacuum coated with gold and examined by SEM using a JEOL JSM 820. Cell size distributions were measured and used to determine the average cell size. Cell density was calculated as the number of cells per unit volume of the unfoamed material using the equation:

$$
N=\left(\frac{n_{b}}{A}\right)^{3 / 2}\left(\frac{\rho_{s}}{\rho_{f}}\right)
$$


where $n_{b}$ is the number of cells in a defined area $A$, and $\rho_{s}$ is the density of the unfoamed solid and $\rho_{\mathrm{f}}$ is the density of the foam.

\section{Compression experiments}

Compressive stress(s) strain $(\varepsilon)$ curves were measured using an Instron machine (model 5500R6025) at room temperature and at a strain rate of $1 \mathrm{~mm} / \mathrm{min}$. The maximum static strain was approximately $75 \%$ for all the experiments. These experiments were used to determine the foam Young's modulus [20,21].

\section{Finite element modelling (FEM)}

The size of the modelled solid pipes was nominal diameter $\mathrm{D}=315 \mathrm{~mm}$, thickness $8 \mathrm{~mm}$, modulus of elasticity of the solid material $\mathrm{E}=200 \mathrm{MPa}$, length of the pipe $\mathrm{L}=300 \mathrm{~mm}$. The pipe thickness was used as an adjustable parameter in the variational analysis. The compressive applied load was selected in order to have a defection near to $3 \%$ of the nominal radius, i.e. $9.45 \mathrm{~mm}$.

The simulation was done in three phases to ensure the convergence of the model.

Initially, the quasi static structural simulation of the configurations was carried out for a $8 \mathrm{~mm}$ thick LDPE pipe. The analysis used a normal Lagrange formulation to consider the change in the contact zone. The mesh was generated using Brick 8node 185 and Mapped Face Meshing elements.

In a second step the simulation was performed using the same type of approximations and meshes but in this case foam pipes were simulated. In order to do that, the relationship between Young's modulus and density of the foam was introduced in each model. 
In a third step, a variational analysis (Goal Driven Optimization) was performed in order to select the density and thickness of the pipe with optimum performance (similar stiffness than that of the dense pipe and minimum weight). The analysis was carried used a multi-objective genetic algorithm (MOGA) which is able to optimize problems with continuous input parameters.

In all cases, the selected input parameters were the foam density, the Young's modulus and the pipe thickness. The response parameters were the maximum pipe deformation, the maximum stress and the pipe weight. The objective was to find out the pipe (density and thickness) with a similar stiffness to that of the dense pipe and with a minimum weight.

\section{RESULTS}

\section{Cellular Structure}

Figure $2 \mathrm{a}$ shows the typical cellular structure of the inner part of one of the foams (density $550 \mathrm{~kg} / \mathrm{m}^{3}$ ). It can be observed that the foam has a very homogeneous closed cell cellular structure. Cells with diameters lower than 50 microns are observed. In addition, the foams presented skin-core morphology as it can be appreciated in figure $2 \mathrm{~b}$ for the same material. The skin has a higher density than the core, giving materials with a spatial mass distribution which in general terms optimises physical properties and surface quality.

Figures $3 \mathrm{a}$ and $3 \mathrm{~b}$ summarises several general trends of the average cell size, and cell density for some of the foams under study. As expected for foams produced using a chemical blowing agents [22] cell size is reduced and cell density is increased when 
density is increased. Appreciable values of cell density (higher than $10^{8}$ cells $/ \mathrm{cm}^{3}$ ) were obtained for high density foams. These values strongly decreased for the lower density foams, which seems to be due to a strong coalescence when the density of the foams was reduced.

By controlling the expansion ratio during the process (figure 1) and the formulation of the precursor materials it was possible to produce foams with relative densities in the range $0.27-0.92$ and with average cell sizes in the range $25-100$ microns, as it is depicted in figure $3 \mathrm{c}$. The possibility offered by the modified compression moulding technique of fabricating foams with a similar density but with a different cellular structure made possible analysing independently the effect on both parameters in the mechanical response as it is explained in the next section.

\section{Mechanical properties}

Figure 4 shows the Young's modulus of the foams as a function of cell size for a given relative density (0.60 in this case). Similar results were found for other densities. It can be observed that both parameters showed constant values in the cell size range between 30 and 100 microns. This result that was also found for low density foams [23], has a significant practical importance because indicates that for materials working in the elastic regime controlling the cell size is not the key objective. Other structural parameters such skin thickness, open cell content, homogenous cellular structure, etc seems to be more important.

As mechanical properties did not showed a dependency with cell size the average values of the Young's modulus for foams of a given density were obtained and analysed as a function of the foams density. Figure 5a shows the experimental results compared with 
two lines that were obtained using a potential law of relative Young's modulus versus relative density (equation 2 ) with exponent $n=1$ and exponent $n=2$. $C$ was assumed to be 1 in these plots [20].

$$
\frac{E_{f}}{E_{s}}=C\left(\frac{\rho_{f}}{\rho_{s}}\right)^{n}
$$

where $E_{f}$ and $\rho_{f}$ are the foam Young's modulus and the foam density and $E_{s}$ and $\rho_{s}$ are the modulus and density of the solid material.

Values of $n$ between 1 and 2 are typical for a wide amount of cellular materials [20], therefore it is expected that most foams, including the ones in this paper, would have properties between these two trends.

The materials under study followed an approximately linear trend given by equation 3 .

$$
\frac{E}{E_{s}}=\left[1.292 \frac{\rho}{\rho_{s}}-0.285\right]
$$

A detailed analysis of figure $5 \mathrm{~b}$ shows different trends depending on the foam density. At high relative densities the mechanical properties of the produced foams are slightly above the linear trend. This shows that in this density range the foams have very interesting mechanical properties. In fact, it can be observed in figure $4 \mathrm{~b}$, that the reduced Young's modulus (modulus divided by density) was higher for these foams than for the solid from which the materials were produced. For relative densities below 0.7 the properties are between the linear trend and the parabolic one. For densities below 0.5 the properties are closer to those of a potential law with exponent 2 . Two different structural sources can be the origin of this non-unique trend with foam density. 
First reason is related with a different thickness of the skin when the foam density was modified. Figure 6 shows that at low densities the skin seems to have a smaller density, which would reduce the mechanical properties. Second reason would be related with the open cell content in the foams. As the low density polyethylene of this study was not crosslinked, it is expected an increase of the open cell content in the materials when the density was reduced, an increase of the open cell content will also reduce the foams stiffness [24].

\section{FEM of the foams behaviour in plastic pipes}

Table 1 shows the results for the finite element modelling comparing the behaviour of a solid pipe with that of the optimum pipe for this application (selected from those produced in the paper). Both pipes were selected with dimensions to asses an equal annular stiffness (the same deformation for a similar applied load). The pipe produced from the solid material had a density of $920 \mathrm{~kg} / \mathrm{m}^{3}$ and a thickness of $8 \mathrm{~mm}$ and the optimum foam had a density of $312 \mathrm{~kg} / \mathrm{m}^{3}$ and a thickness of $14.3 \mathrm{~mm}$. It was calculated (last column) that the pipe produced with the foam has a smaller weight (1.2 $\mathrm{kg}$ in spite of $2.1 \mathrm{~kg}$ ), therefore a $42 \%$ reduction in weight was obtained for a similar annular stiffness.

In addition, another advantage is that the maximum stress on the pipe was much smaller for the cellular material than for the continuous solid material (table 1 and figure 7 ). In this case the reduction was much higher, from $1.37 \mathrm{MPa}$ to $0.42 \mathrm{MPa}$ (a $69 \%$ reduction). 
Finally, a map for pipes with equivalent bending stiffness was obtained (figure 8). In this diagram the mass of the pipe is presented as a function of the foam density, three types of materials are considered. First, ideal materials, following a power law relationships between modulus and density with exponent equal to one, second typical foams that it is known [20] follow a power law relationships between modulus and density with exponent equal to two, and third the materials analysed in this paper that follow the relationships given in equation 3 .

Several interesting conclusions are obtained. On the one hand it can be concluded than for pipes loaded in compression, the minimum weight for a given stiffness is reached by using low density foams; in other words it can be said that for this geometry foams are stiffer materials than solids at equivalent weight. On the other hand, the maximum weight reduction (minimum panel weight) is obtained for materials with a power law with exponent equal to one, followed by the materials in this study and the materials following a quadratic trend with density. The weights reductions for a relative density of 0.5 are: linear law 36\%, experimental data $26 \%$, quadratic law $17 \%$. These data clearly point out the importance of producing foams in which the mechanical properties at low strains could take values close to the linear relationship. As it can be observed in the data, the materials produced in this paper give very close weight reductions to the ideal trend for high density foams and intermediate values between the optimum values and the ones obtained using the quadratic trend for mediums and lower density foams.

\section{SUMMARY AND CONCLUSIONS.}

A collection of high density polyethylene foams with cell sizes in the microcellular range have been produced using a novel procedure based on a modified compression 
moulding technique. This process allows controlling the foam density and the cell size in an independent way.

The cellular structure of the foams was very homogeneous with cell sizes around 50 microns, having the materials a skin-core morphology. The cell size increased and the cell density decreased with a reduction of the density as it is expected for materials produced from a chemical blowing agent. Materials with different cell sizes for a given density were produced, but no improvement of the Young's modulus and the collapse stress was obtained using this strategy. The Young's modulus followed a linear trend with values slightly above the theoretical limit for relative densities above 0.7 , which seems to be due to the presence of a thick skin. Using finite element modelling it has been demonstrated that the materials can be used to produce light weight structural pipes. Weight reductions up to $42 \%$ can be reached using foams with densities in the range of $300 \mathrm{~kg} / \mathrm{m}^{3}$.

\section{Acknowledgements}

Financial assistance from the Local Government (Junta of Castile and Leon (VA047A07), Spanish Ministry of Education and Science and FEDER program (project MAT 2006 1614-C03-01) is gratefully acknowledged.

\section{REFERENCES}

1. K.T. Okamoto, Microcellular Processing, Hanser Publishers, Munich 2004.

2. C.B. Park in Foam extrusion: Principles and Practise, Ed. S. T. Lee, Technology Publishing Company, USA, 2000, Chapter 11.

3. J. Colton and N.P. Suh, Polymer Engineering and Science, 27, 485, 1987. 
4. R. E. Murray, J.E. Weller and V. Kumar, Cellular Polymers, 19, 413, 2000.

5. V. Kumar and J.E. Weller, International Polymer Processing, 8, 73. 1993

6. K.A. Arora, A.J. Lessor and T.J. McCarthy, Macromolecules, 31, 4614, 1998.

7. V. Kumar, M. VanderWel, J.E. Weller, and K.A. Seeler, Journal of Engineering Materials and Technology, 116, 439, 1994

8. G. Wing, A. Pasricha, M. Tuttle and V. Kumar, Polymer Engineering and Science, 35, 673, 1995

9. H. Sun, G.S. Sur, J. E. Mark, European Polymer Journal 2002, 38, 2373-2378.

10. H. Sun, J.E.Mark, J. Appli.Polym. Sci., 86, 1692-1701, 2002.

11. J.E. Martini, N.P Suh and F.A. Waldman, US patent 4473655, 1984

12. V. Kumar, in Handbook of Polymeric foams, Ed: David Eaves, Rapra Technology, UK 2004, Chapter 10.

13. C.B. Park, A.H. Behravesh and R.D. Venter, Polymeric Foams: Science and Technology, Ed., K.C. Khemani, ACS Symposium Series No.669, ACS, Washington, DC, USA, 1997.

14. B. Seibig, Q. Huang and D. Paul, Cellular Polymers, 19, 93, 2000.

15. A.J. Bledzki, J. Kuhn, H. Kirschiling. W. Pitscheneder, Cellular Polymers, 27, 91-100, 2008.

16. Puri RR, Collington KT. Cellular Polymers, 7:57, 1988.

17. Puri RR, Collington KT. Cellular Polymers, 7, 219, 1988.

18. D. Eaves, in Handbook of Polymeric Foams, Edited by. D Eaves, Rapra Technology, UK, 2004

19. M.A. Rodriguez-Pérez, M.A.del Carpio, J.F. Lopez-Díaz, J.A. de Saja, Procedure to produce moulded pipes with cranial microcellular structure, Spanish Patent $n^{\circ}$ P200602638, 2006 (PCT applied 2007) 
20. L.J. Gibson, M:F. Ahsby, Cellular Solids, Structure and properties, Cambridge University Press, UK, 1997.

21. M.A. Rodríguez-Pérez, J.I.Velasco, D.Arencón, O.Almanza, J.A. de Saja, J. Appl. Polymer Sci, 75, 156-166, 2000.

22. M.A. Rodríguez-Pérez, O. Almanza, J L. Ruiz-Herrero, J.A. de Saja, Cellular Polymers, in press, 2008

23. M.A. Rodríguez-Pérez, J.I. González-Peña, N.Witten, J.A. de Saja, Cellular Polymers, 21, 165-194, 2002.

24. M.A. Rodríguez-Pérez, Cellular Polymers 21, 117-136, 2002 


\section{Caption of Figures}

Figure 1. Schematic diagram showing the last step of the modified compression moulding technique. The expansion ratio (ER) is controlled by the piston displacement. Figure 2. SEM micrograph of the inert part of one of the produced materials (density $\left.550 \mathrm{~kg} / \mathrm{m}^{3}\right)$

Figure 3. a) Average cell size vs. relative density, b) Cell density vs. relative density c) Density and cell size of the analysed foams.

Figure 4. a) Relative Young's modulus as a function of cell size for foams with a relative density of 0.6 . b) Reduced Young's modulus as a function of density Figure 6. Relative Young's modulus as a function of density Figure 7. Presence of a more dense skin in samples with a higher density.

Figure 8 . Equivalent stress distribution of a) solid polymer b)foam of $310 \mathrm{~kg} / \mathrm{m}^{3}$ in density.

Figure 9. Mass of vs foam density for pipes with equal stiffness. The three curves correspond (linear) materials following a power law relationships with exponent equal to one, (quadratic) materials following a power law relationships with exponent equal to two, and (experimental data) the materials analysed in this paper that follow the relationships given in equation 3 
Figure 1

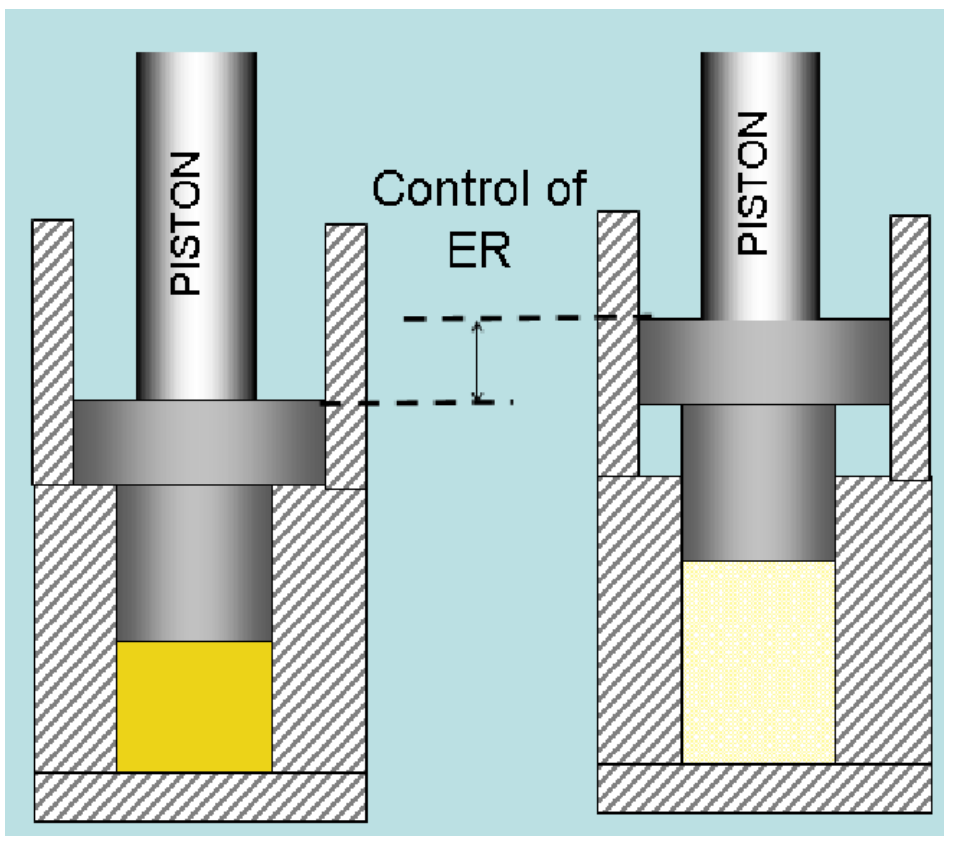


Figure 2

a)

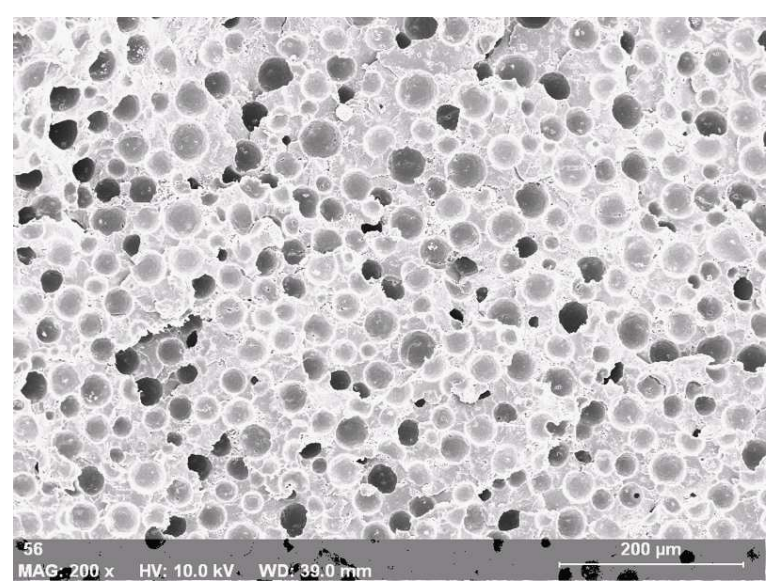

b)

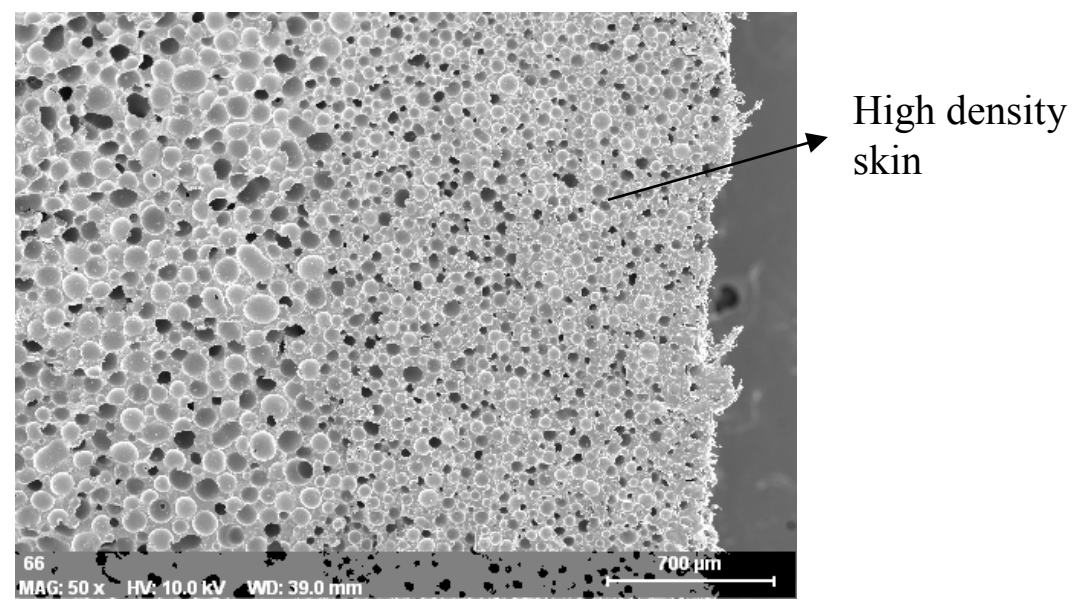


Figure 3
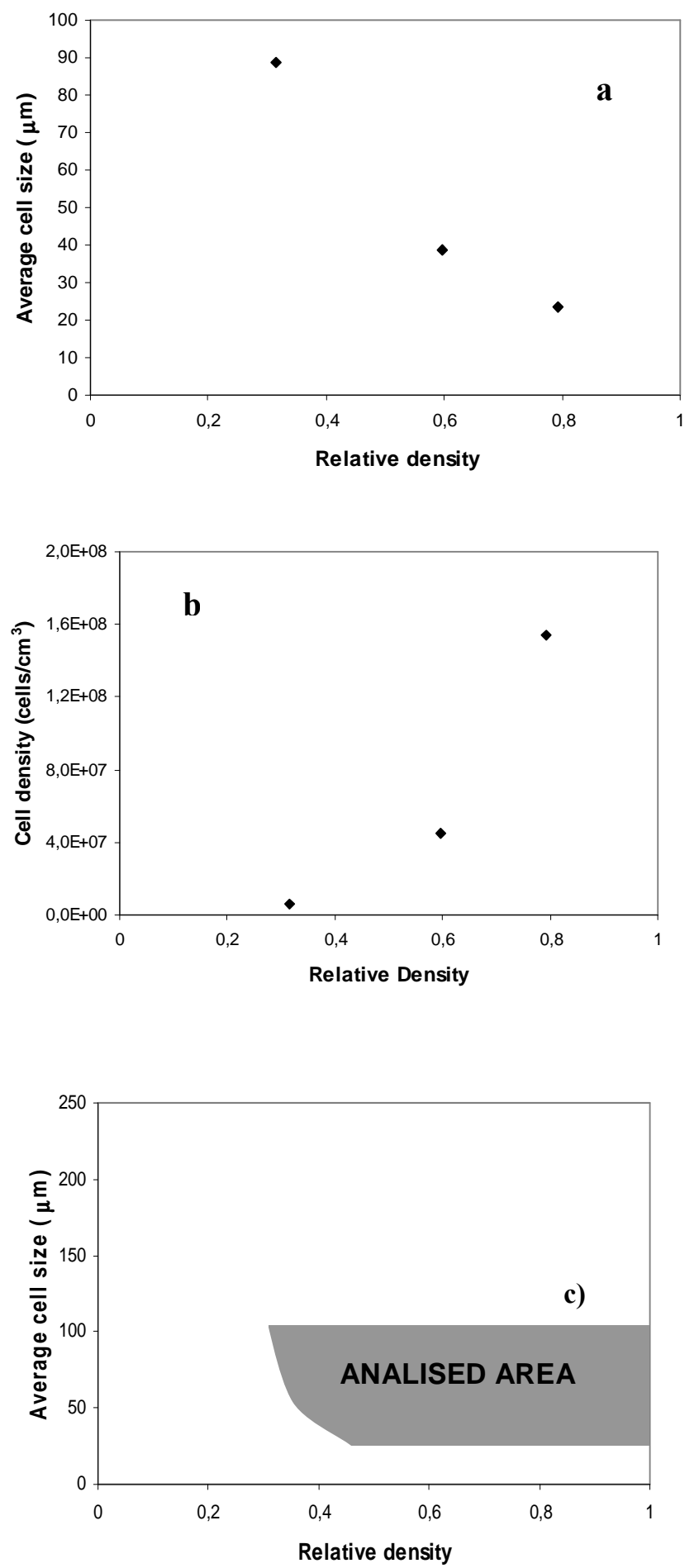
Figure 4

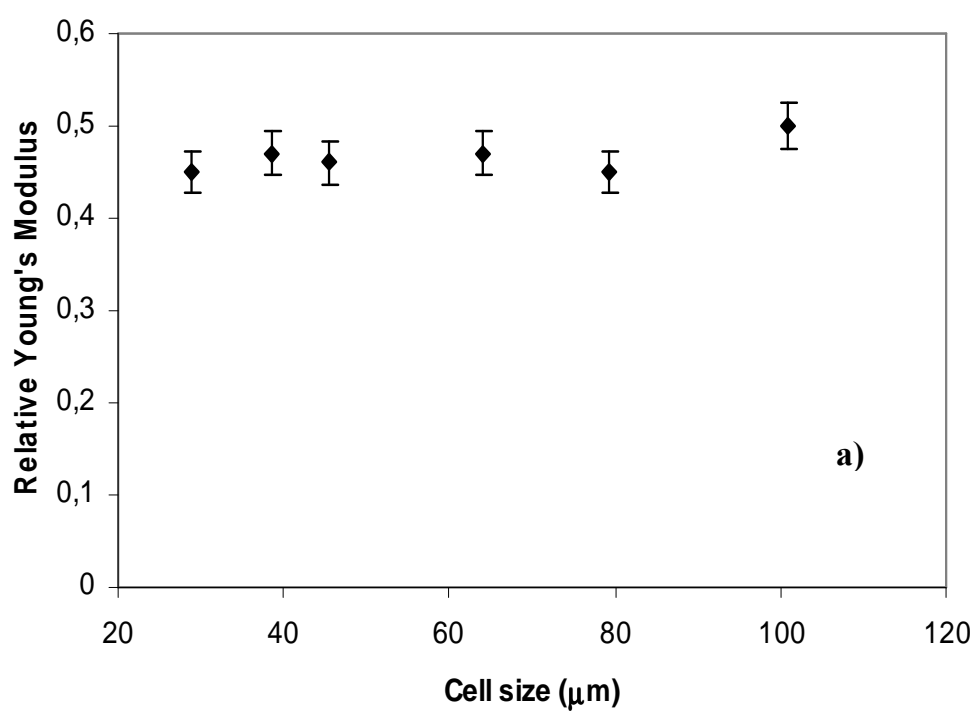


Figure 5
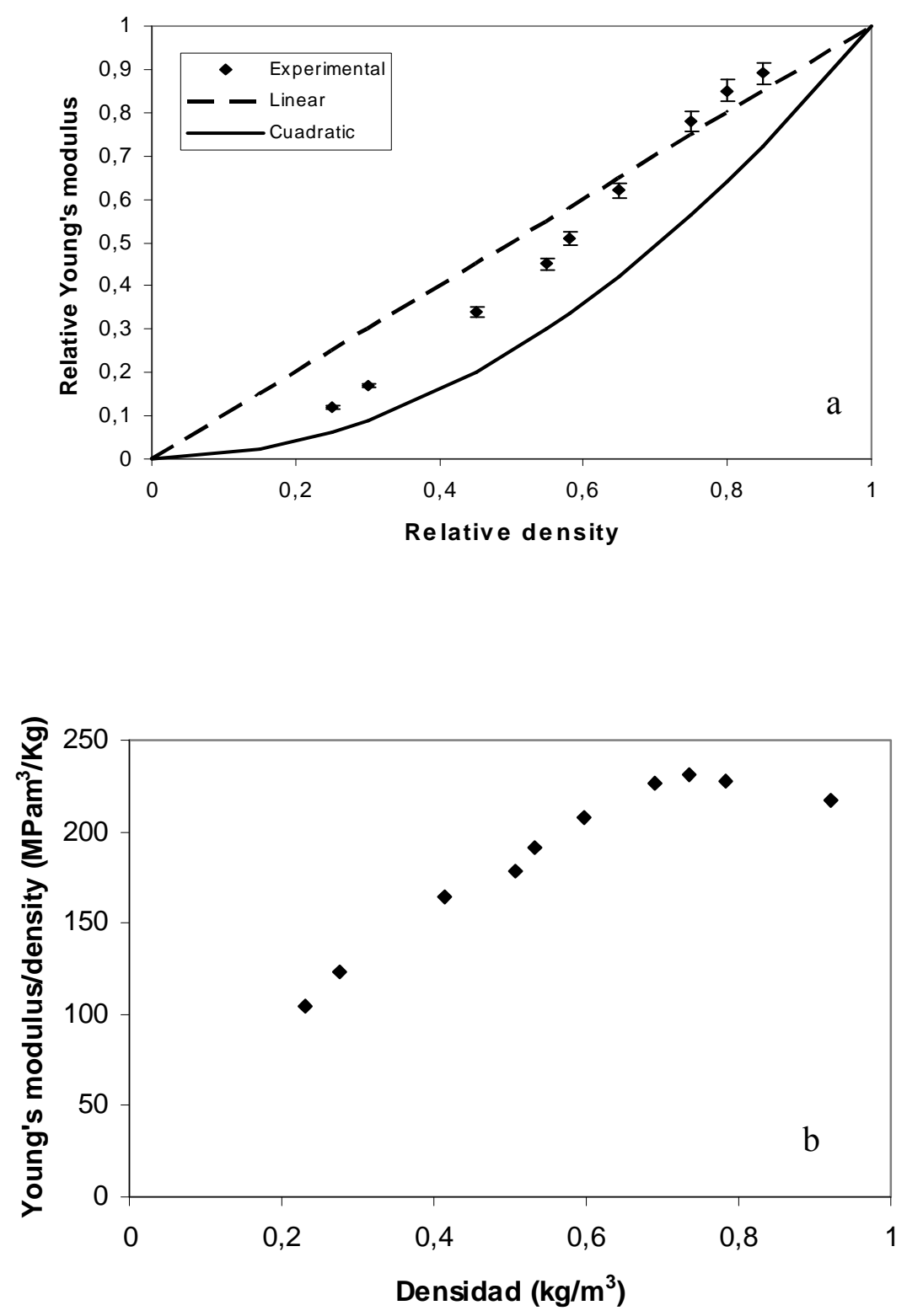
Figure 6

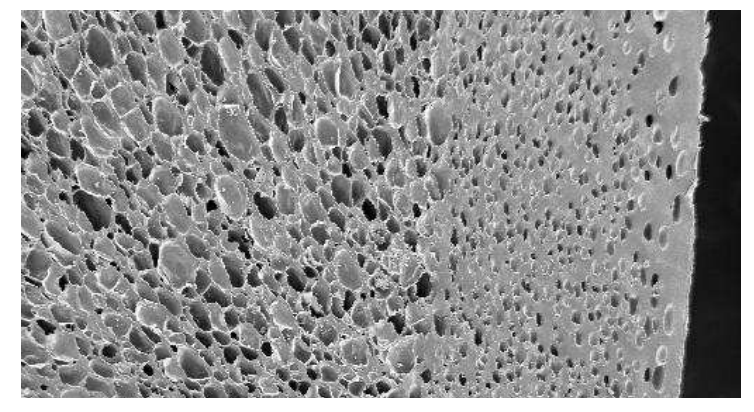

density $730 \mathrm{~kg} / \mathrm{m}^{3}$

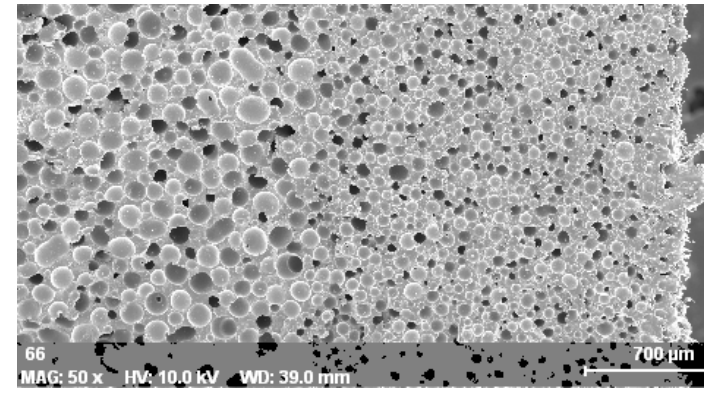

density $550 \mathrm{~kg} / \mathrm{m}^{3}$

Figure 7 
a

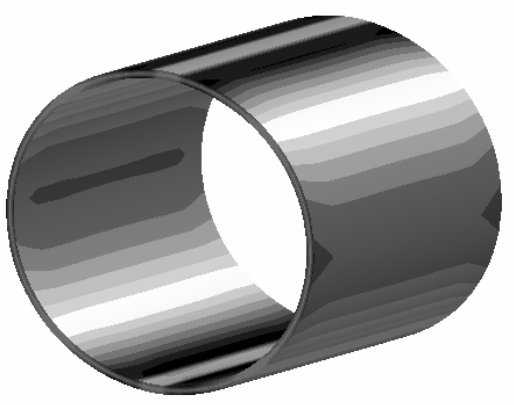

\begin{tabular}{ll|l|l|l|}
$\mathbf{1 , 3 6 5 8 \operatorname { m a x }}_{1,0064}$ & $\left.\right|_{0,76692}$ & $\left.\right|_{0,46747}$ & $\left.\right|_{0,16003}$
\end{tabular} b

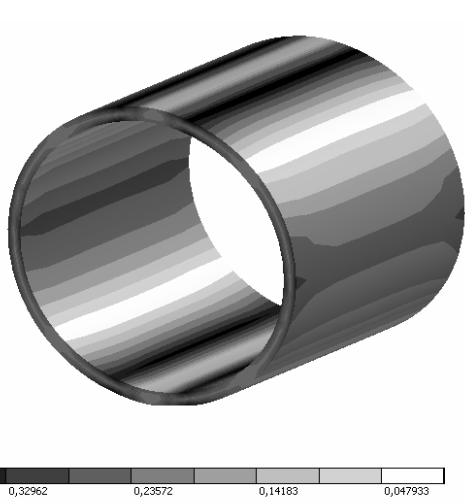


Figure 8

PEDIR A CESAR ESTA FIGURA 


\begin{tabular}{|l|l|l|l|l|l|}
\hline Case & Thickness (mm) & Density $\mathbf{( k g / \mathbf { m } ^ { 3 } )}$ & $\begin{array}{l}\text { Deformation } \\
(\mathbf{m m})\end{array}$ & Stress (MPa) & Mass (kg) \\
\hline Solid Pipe & 8 & 920 & 9.43 & 1.37 & 2.1 \\
\hline $\begin{array}{l}\text { Foamed } \\
\text { Pipe }\end{array}$ & 14.3 & 312 & 9.34 & 0.42 & 1.2 \\
\hline
\end{tabular}

